As regards the measurement of diameters, although an ordinary micrometer will suffice for the external dimension, it is not suitable for determining either the effective or the core diameter. Before testing the effective diameters it is necessary to know the errors of the pitch, in order that the appropriate reductions may be made in the maximum limit of tolerance. A micrometer with point contacts should never be used alone for the effective diameter, as it bears only on projecting parts, and, further, the points wear down quickly. Even when new, its contacts for screwthreads rarely have the correct angle. It is, however, a useful check on results obtained by the aid of wire contacts, especially for investigating anomalies which may be apparent in these results.

Mr. Powell has made a special study of wire contacts for testing effective diameters. He employs systematically two series of wires for each pitch of screw. One series is such that the wire bears exactly on the theoretical effective diameter of a perfect screw; in the other series the wire bears on the sides of the screw not far from the outer edge, but so as to avoid the rounded-off part in Whitworth threads. The correct diameters for the series are calculated from a simple formula. The wires, which are finished by grinding, must be perfectly cylindrical, and their diameters have to be ascertained to an accuracy of $0.0000 \mathrm{I}$ in.; any error in the diameter of the wire is multiplied threefold in the result obtained for the effective diameter. They are made of hardened steel, and are about 2 in. in length, or longer for very large screws; but their exact adjustment is only necessary over about half an inch in the centre of the lenoth.

The verification of internal screws may be effected simply by embloving either an external screw having the correct dimensions for external, effective, and core diameters, or a screw correct for maximum and effective diameters, but slightlv small for core diameter. A plug is also used in this case for verifying the minimum diameter of the internal screw. If these gauges enter the nut, the test is resarded as satisfactorv; but, in reality, this is not alwavs the case, as the external screw may appear to give a good result even if it bears on only one diameter of the nut; while the other diameters may be far outside the limit of tolerance. A large number of different gauges are necessary in order to verify separately every diameter of an internal screw.

Mr. Powell has drawn up a list of equipment required in the verification of screw gauges. This includes a pitch-measuring machine, an apparatus for obtaining casts of internal screws, a projecting arrangement, an instrument for measuring the three characteristic diameters of external screws, a collection of suitable wire contacts, small triangular prisms for verifving core diameters, standardised micrometers, Johansson gauges, and a complete set of standards for measuring diameters, pitch, and form of internal threads.

A theoretical explanation of the principles of the methods employed would have been of interest. In its absence some doubts arise, for example, as to the practical value of profiles of screw-threads projected on screens. Again. the contacts of small cvlindrical wires on the helicoidal surfaces of threads cannot be regarded as the same as that of a circle and two intersecting straight lines, although the formula emploved, which are stated without proof. apnear to be founded on a consideration of this kind. In conclusion, Mr. Powell's methods are bv no means entirelv novel, but thev were verv successful during the war, and will no doubt be found instructive by all those engaged in the manufacture and verification of screw gauges. NO. 2632 , VOL. IO5]

\section{The Composition of Salvarsan.}

WHEN salvarsan was first introduced for use in medicine the German manufacturers stated that it contained "about 34 per cent. of arsenic," which is the percentage calculated for a pure dihydroxydiaminoarsenobenzene dihydrochloride, $\mathrm{C}_{12} \mathrm{H}_{12} \mathrm{O}_{2} \mathrm{~N}_{2} \mathrm{As}_{2}, 2 \mathrm{HCl}$. This statement was afterwards altered to "the arsenic content of the preparation corresponds to the formula $\mathrm{C}_{12} \mathrm{H}_{12} \mathrm{O}_{2} \mathrm{~N}_{2} \mathrm{As}_{2}, 2 \mathrm{HCl}, 2 \mathrm{H}_{2} \mathrm{O}$ as a result of Gaebel's observation that the drug loses $7 \cdot 6$ per cent. by weight on drying, and contains only $3 \times \cdot 5$ per cent. of arsenic." Last year Kober, in the United States, ventured the opinion that the combined solvent in salvarsan is not water, but methyl alcohol, and suggested that the latter might be the cause of variable toxicity in salvarsan-a suggestion which is rather far-fetched in view of the fact that, even on Kober's assumption, a maximum normal dose of salvarsan could contain only 0.04 gram of methyl alcohol.

This and other questions connected with the composition of salvarsan have been investigated in the Wellcome Chemical Research Laboratories, and in a paper contributed to the meeting of the Chemical Society on March I8 Messrs. Fargher and Pyman showed that the combined solvent in salvarsan is water: and though small quantities of methyl alcohol may also be present, due to the use of this alcohol in the liquid from which the drug is precipitated, the amount never exceeds $\mathrm{x} .4$ per cent., and is frequently nil. It was also found that the sulphur always present in commercial salvarsan as a result of the use of sodium hyposulphite as a reducing agent in its preparation, occurs in at least two forms: (I) as a sulphaminic acid, probably "salvarsan" monosulphaminic acid hydrochloride, and (2) attached directly to arsenic; whilst a third portion may be in physical association with salvarsan, which has certain colloidal properties.

These results support the conclusion expressed in the recent Special Report (No. 44) of the Medical Research Committee, that though salvarsan is not a chemically pure substance, there is no known chemical impurity with the presence or proportion of which its varying toxicity can be brought into relation. In this connection it is interesting to note that a specially pure salvarsan free from sulphur, prepared by Messrs. Fargher and Pyman, was tested by the Medical Research Committee and shown to be more than normally toxic. Chemical testing alone is, therefore, insufficient to determine whether any particular batch of salvarsan is suitable for medical use, and it is on this account that the Medical Research Committee has elaborated the system of biological testing, described in the Special Report already referred to, to control the issue of salvarsan in this country. It is satisfactory that the Committee is able to report is satisfactory that point of view of permanence of effect, the British and French salvarsan preparations are therapeutically as good as the German.

\section{University and Educational Intelligence.}

THE governors of the Huddersfield Technical College have received a gift of $2000 l$. from Mrs. Mary Blamires, widow of Alderman Joseph Blamires, in memory of her late husband, himself a former student, and afterwards a governor, of the college. The scholarship is to be used for the promotion of research in chemistry.

THB headquarters of the Yorkshire Summer School of Geography, now being organised by the University of Leeds, will this year be the County School, Whitby 
the school buildings having been kindly lent by the governors for this purpose. The object of the Summer School is to provide theoretical and practical instruction in the methods of geography and to furnish opportunities for the discussion and elucidation of problems connected with the teaching of the subject. The course will consist of lectures, laboratory work, field work, and demonstrations. Lectures will begin on Morning morning, August 2, and the course will end on Saturday, August 2I. Among the lecturers will be Prof. Kendall (professor of geology in the University of Leeds), Dr. A. Gilligan (lecturer in economic geology), Mr. C. B. Fawcett (lecturer in geography), Dr. W. G. Smith (lecturer in agricultural botany at the Edinburgh and East of Scotland Institute), and Mr. W. P. Welpton (lecturer in education and master of method in the University of Leeds). Applications for tickets should be made to the Secretary of the Yorkshire Summer School of Geography, The University, Leeds.

BEDFORD College for Women, a constituent college of the University of London, and the largest and oldest university college for women in England, has issued an appeal for funds. At the moment, when there is an overwhelming demand by women for higher education and training, the college must either refuse admission to highly suitable students and starve or close down certain departments, or it must enlarge its buildings and increase its endowments. Seven hundred students now crowd into buildings adapted for four hundred and fifty, with the result that in many cases classes have to be triplicated and classrooms and apparatus shared between different departments. A sum of $100,000 l$. is needed for additional lecture-rooms and laboratories. A second 100,00ol. is required for endowment, notably for scholarships, the various departments of science, the department of social studies, and the training department. A third $100,000 l$. is badly needed for a hostel. An opportunity for acquiring an admirable site just outside Regent's Park has presented itself. Whether the college can take advantage of this must depend on the generosity of the public. It should, perhaps, be emphasised that, apart from such developments, the income of the college is by no means sufficient for its present needs in view of the enormously increased cost of maintenance and the necessity for raising all salaries. The work of universities in the past could never have been done had there not lived generous men and women who believed thev could render no greater public service than by endowing colleges and thus furnishing opportunities for rich and poor to acquire sound learning. May we hope that a like generosity and a like belief exists to-day? The Queen's interest in the college is well known, and has taken the practical form of giving a donation. Subscriptions should be sent to Viscountess Elveden, hon. treasurer of the Bedford College Endowment and Extension Fund, Bedford College, Regent's Park, N.W.I.

\section{Societies and Academies.}

\section{LONDON.}

Royal Society, March r8.-Sir J. J. Thomson, president, in the chair.-W. B. Brierley : A form of Botrytis cinerea with colourless sclerotia. A form of Botrytis cinerea with colourless sclerotia is described. This was obtained by the isolation and growth of a colourless sclerotium, which was formed in a culture of a normal strain derived from a single spore. The primary origin of the change resulting in the albino form is located in the hyphal mother-cell from which

$$
\text { NO. } 2632 \text {, VOL. IO5] }
$$

the initial colourless sclerotium arose. Lotsy's dictum that "certainty of purity is a conditio sine qua non to obtain proof of the existence of mutation in living beings" is accepted, and it is shown that such a state is possibly not realisable in the fungi. It is suggested that somatic fusions resulting in a change of genotypic values are the mechanism whereby evolution in the fungi has taken place.-R. R. Gates: A preliminary account of the meiotic phenomena in the pollen mother-cells and tapetum of lettuce (Lactuca sativa). In a preliminary study of meiosis in the pollen development of lettuce, several points have appeared which have a general bearing on cytological conceptions and the problems of genetics. The exceptional condition has been found in lettuce, in which every intergrade occurs between pollen mother-cells and tapetal cells. Even synapsis has been obseryed in binucleate tapetal cells, which emphasises the physiological aspects of the synaptic contraction. The tapetal cells are peculiar in being often very much elongated and lying lengthwise of the anther. Ultimately they break down and form a plasmodium surrounding the pollen-grains. Cytomyxis also occurs, though rarely, during the stage of synapsis in the pollen mother-cells.

March 25.-Sir J. J. Thomson, president, in the chair.-A. R. Forsyth : Note on the central differential equation in the relativity theory of gravitation. The critical equation in Prof. Einstein's theory is-

$$
\text { so that } \quad\left(\frac{d u}{d \phi}\right)^{2}=2 m(u-a)(u-\beta)(u-\gamma) \text {, }
$$

where $\alpha, \beta, \gamma$ are proved to be real and positive for the known planetary bodies in the solar system, and are arranged so that $\alpha>\beta>\gamma$.

There is no need for initial approximation. The equation can be integrated exactly, in terms of elliptic functions. The integral is-

$$
u=\gamma+(\beta-\gamma) \frac{\mathrm{I}+c n\{(\phi-\varpi) / \rho\}}{\mathrm{I}+d n\{(\phi-\varpi) / \rho\}}
$$

where $\phi=$ at perihelion; the modulus of the elliptic functions is given by-

$$
k^{2}=\frac{\beta-\gamma}{a-\gamma} \text { and } \rho=\{2 m(\alpha-\gamma)\}^{-\frac{1}{2}} \text {. }
$$

Further, the advance of the perihelion in one revolution is-

$$
4 \rho \mathrm{K}-2 \pi \text {, }
$$

where $\mathrm{K}$ is the complete first elliptic integral with the modulus $k$. These expressions are accurate (and not approximate) in relation to the initial equation. For approximations in connection with the known members of the solar system, $k^{2}$ is small, so that $\mathrm{K}$ is slightly greater than $\frac{1}{2} \pi$, and $\rho$ is slightly greater than unity. The advance of the perihelion is $2 \pi \cdot 3 \mathrm{~m}^{2} / \lambda^{2}$; and the value of $u$ is-

$$
\begin{aligned}
\lambda^{2}\{\mathrm{I}+e \cos (\phi-\varpi) & +\frac{m^{2}}{\lambda^{2}} e^{2} \sin ^{2}(\phi-\varpi) \\
& \left.+3 \frac{m^{2}}{\lambda^{2}} e(\phi-\varpi) \sin (\phi-\omega)\right\} .
\end{aligned}
$$

-R. D. Oldham: The frequency of earthquakes in Italy in the years 1896 to 1914 . The paper is an attempt to discover whether there is any variation in the frequency of earthquakes which can be attributed to the stresses set up by the gravitational attraction of the sun and the moon. In addition to some small and more or less doubtful variations, there was found to be a very marked maximum frequency about the time of the new moon, when the declinations of the sun and moon were of the same sign and at the full 